\title{
Clinical Features of Acute Allergic Reactions to Peanut and Tree Nuts in Children
}

\author{
Scott H. Sicherer, MD*; A. Wesley Burks, MD¥; and Hugh A. Sampson, MD*
}

ABSTRACT. Background. Peanut (PN) and tree nut (TN) allergies are potentially life-threatening, rarely outgrown, and appear to be increasing in prevalence. However, there is relatively little reported about the clinical features of acute reactions to these foods and their potential association.

Objective. To describe the clinical features of acute reactions during initial and subsequent accidental ingestions of PN and TN among children with a history of at least one acute allergic reaction to these foods.

Design. Questionnaire survey, examination, and serologic testing for specific IgE antibody of patients with convincing histories of acute reactions (at least one organ system involved within 60 minutes of ingestion) to PN or TN.

Results. A total of 122 patients (63\% males; median age, 8 years at time of study) had acute reactions; 68 had reactions only to $\mathrm{PN}, 20$ only to $\mathrm{TN}$, and 34 to both $\mathrm{PN}$ and TN. Of those reacting to $\mathrm{TN}, 34$ had reactions to one, 12 to two, and 8 to three or more different TN, the most common being walnut, almond, and pecan. Initial reactions usually occurred at home (median age, 24 months for $\mathrm{PN}$ and 62 months for $\mathrm{TN}$ ) and were considered to result from a first exposure in $72 \%$ of cases. Eighty-nine percent of the reactions involved the skin (urticaria, angioedema), 52\% the respiratory tract (wheezing, throat tightness, repetitive coughing, dyspnea), and $32 \%$ the gastrointestinal tract (vomiting, diarrhea). Two organ systems were affected in $31 \%$ of initial reactions, and all three in $21 \%$ of reactions. Thirty-eight of 190 first reactions to PN or TN were treated with epinephrine. Accidental ingestions occurred in $55 \%$ of $\mathrm{PN}$-allergic children (average of two accidents per patient with an accidental ingestion) and in $30 \%$ of TN-allergic children over a median period of 5.5 years. On average, symptoms after accidental exposure were generally similar to those at initial exposure. Accidents occurred commonly in school but also at home and in restaurants. Modes of accidental ingestion included sharing food, hidden ingredients, cross-contamination, and school craft projects using peanut butter. Eighty-three percent of the children were breastfed, with $>90 \%$ of the mothers ingesting $\mathrm{PN}$ and at least one TN during lactation. Among patients reporting no history of exposure ( $>60 \%$ of patients for each $\mathrm{TN}$ ), IgE antibodies were found to a particular TN in $50 \%$ to $82 \%$ of patients and to $\mathrm{PN}$ in $100 \%$ of patients.

From the *Division of Allergy/Immunology, Department of Pediatrics, Jaffe Food Allergy Institute, Mount Sinai Hospital, Mount Sinai School of Medicine, New York, New York, and the łDivision of Immunology and Allergy, University of Arkansas for Medical Sciences, Arkansas Children's Hospital, Little Rock, Arkansas.

Received for publication Dec 1, 1997; accepted Mar 3, 1998.

Reprint requests to (S.H.S.) Department of Pediatrics, Mount Sinai Hospital, Box 1198, One Gustave L Levy Pl, New York, NY 10029.

PEDIATRICS (ISSN 0031 4005). Copyright $\odot 1998$ by the American Academy of Pediatrics.
Conclusions. Acute allergic reactions to $\mathrm{PN}$ occur early in life. PN and TN allergic reactions coexist in one third of PN-allergic patients, frequently occur on first known exposure, and may be life-threatening, requiring emergency treatment. Accidental ingestions are common, occur frequently outside of the home, and often require emergency treatment. Consequently, early diagnosis followed by education on avoidance and treatment measures (including self-administered epinephrine) is imperative. Pediatrics 1998;102(1). URL: http://www. pediatrics.org/cgi/content/full/102/1/e6; peanut, food hypersensitivity, anaphylaxis, tree nuts.

ABBREVIATIONS. PN, peanut; TN, tree nut; GI, gastrointestinal; CAP System FEIA, a quantitative antibody fluoroscein-enzyme immunoassay; RAST, radioallergosorbent test.

$\mathrm{P}$ eanut $(\mathrm{PN})$ and tree nuts (TN) are particularly important allergenic foods, but there is a paucity of reports about the clinical features of acute reactions to these foods. Unlike allergy to foods such as milk, egg, soy, and wheat, allergic sensitivities to PN and TN are rarely outgrown. ${ }^{1-4}$ In addition, allergic reactions to $\mathrm{PN}$ and TN are often severe, and these allergens are most frequently associated with fatal reactions. ${ }^{5-7}$ The common consumption of PN among young children and the apparent increasing prevalence of allergic reactions to PN make additional research in this area vital. 8,9 The sensitization of patients to both PN (a legume) and to TN has been commonly observed, but the extent and clinical relevance of this cosensitization remain uncertain. . $^{2,6,10}$

We undertook the present study to better characterize the nature of acute allergic reactions to $\mathrm{PN}$ and TN in children. A detailed history was obtained with the aid of a questionnaire, and specific IgE antibody levels were determined on pediatric patients presenting with a history of at least one acute reaction to $\mathrm{PN}$ and/or TN.

\section{SUBJECTS AND METHODS}

From December 1995 to May 1997, a detailed clinical history was obtained with the aid of a structured questionnaire from children evaluated in the Pediatric Allergy Clinic at Johns Hopkins Hospital, who had experienced at least one acute reaction to $\mathrm{PN}$ or TN. Reactions were considered to be convincing if ingestion of the suspected food resulted in a reaction involving one or more symptoms in one or more of the following organ systems (skinhives, edema; respiratory-wheezing, throat tightness, repetitive coughing, shortness of breath; or gastrointestinal (GI) tract-vomiting, diarrhea) within 60 minutes of exposure. Histories generally were not confirmed by oral food challenges.

Because cosensitization to $\mathrm{PN}$ and TN is frequently reported, sera were analyzed for specific IgE antibody levels to PN, a panel 
of $\mathrm{TN}$, and sesame seed (known to have cross-reacting proteins with hazel nut ${ }^{11}$ ) with the CAP System quantitative antibody fluoroscein-enzyme immunoassay (FEIA) (Pharmacia and Upjohn Diagnostics, Uppsala, Sweden). ${ }^{12}$ Serum samples were not obtained from 11 patients for reasons such as technical difficulty and parental preference. The lower limit of the assay is $<0.35 \mathrm{kU}_{\mathrm{A}} / \mathrm{L}$ and the upper limit for undiluted serum is $>100 \mathrm{kU}_{\mathrm{A}} / \mathrm{L}$. For statistical analysis, values below detection were arbitrarily assigned a value of $0.34 \mathrm{kU}_{\mathrm{A}} / \mathrm{L}$, and those $>100 \mathrm{kU}_{\mathrm{A}} / \mathrm{L}$, a value of $101 \mathrm{kU}_{\mathrm{A}} / \mathrm{L}$. Statistical comparisons were performed with the Man$\mathrm{n}$-Whitney $U$ test and the Spearman correlation coefficient $\left(r_{\mathrm{S}}\right)$.

\section{RESULTS}

\section{Subjects}

The characteristics of the 102 patients experiencing an acute reaction to $\mathrm{PN}$ and the 20 experiencing acute reactions to at least one $\mathrm{TN}$ (but not to $\mathrm{PN}$ ) are shown in Table 1 . Of the 122 patients, there were 78 males $(63 \%)$ and the median age at the time of evaluation was 8 years. There were 110 Caucasians, 8 African-Americans, and 4 Asian-Americans. The group was highly atopic and food-allergic, reflecting our tertiary referral population. Seventy-four percent had asthma, and 75\% had atopic dermatitis. Eightyone of the patients had a history of allergy to foods other than PN or TN; the majority of these food allergies were confirmed by convincing histories with supporting positive allergy skin prick tests, food-specific serum IgE antibody levels, and/or oral food challenges. The most common foods were egg (70 patients), milk (45), shellfish (18), fish (17), soy (14), and wheat (12). All but 9 patients had injectable epinephrine available for use in case of an accidental ingestion. Of these 9, 3 had not been prescribed the medication before referral, and the remainder forgot to renew prescriptions.

\section{Types of Nuts Responsible for Reactions}

Of the 102 patients with acute reactions to PN, 34\% experienced reactions to at least one TN. The TN responsible for acute allergic reactions among 54 patients are shown in Fig 1. Among the patients with reactions to $\mathrm{TN}, 34(63 \%)$ experienced a reaction to only one type, $12(22 \%)$ to two types, and $8(15 \%)$ had reactions to three or more types. Walnut, almond, pecan, and cashew were the most common TN responsible for reactions.

\section{First Allergic Reactions to PN}

Table 2 lists the characteristics of first reactions to PN. Seventy-two percent experienced a reaction with their first known exposure to PN (median age, 24 months; range 6 to 108 months). The median time to onset of symptoms was 3 minutes, with a range of $<1$ minute to 45 minutes, with $95 \%$ of patients experiencing symptoms within 20 minutes. Whereas half of the patients experienced isolated skin symptoms, very few (4 patients) experienced isolated GI or respiratory symptoms. None of the patients reported cardiovascular compromise, loss of consciousness, or decreased blood pressure.

Medications used for treatment included antihistamines $(73 \%)$, epinephrine $(19 \%)$, corticosteroids $(13 \%), \beta$-agonists (13\%), and intravenous fluids ( $2 \%)$. Twenty-two patients were not given any medication at the time of their first reaction. Most patients were treated at home (51), whereas the remainder were treated in an emergency room (21), a doctor's office (11), in school (3), at a relatives home, or in a car (1 each). Eight patients were treated first at home, and then treatment was continued in an emergency room or physician's office.

\section{First Allergic Reactions to TN}

The characteristics of first acute allergic reactions to TN are summarized in Table 2; 88 episodes occurred in 54 patients. Although most of the characteristics were similar to those noted for PN, the median age of exposure (22 versus 54 months) and first reactions (24 versus 62 months) were significantly greater $(P<.001)$ in patients reacting to TN. Treatments for these first episodes of allergic reactions to TN included antihistamines (70 patients), epinephrine (19), corticosteroids (12), $\beta$-agonists (14), intravenous fluids (4), and intubation (1). The location of the treatment for the reaction was reported in 65 cases: home (36), emergency room/hospital (17), doctors office (3), school (4), and other places including homes of relatives or friends (5).

\section{Accidental Ingestions}

Over a median period of 5.4 years from the time of the initial reaction, $55 \%$ of $\mathrm{PN}$-allergic patients experienced reactions to accidental ingestions of $\mathrm{PN}$, with an average of two accidents per patient among those reacting (range, one to five episodes). The median age at the time of a first accidental ingestion was 4 years. Accidental ingestions occurred most commonly in school (29), home (22), and restaurants (8). The symptoms were similar to those of the first reaction: skin only, 44\%; respiratory only, 10\%; GI only, 3\%; skin with respiratory, $18 \%$; skin with GI, $8 \%$; GI with respiratory, $2 \%$; all three systems, $15 \%$. One patient experienced loss of consciousness. Treat-

TABLE 1. Demographic Characteristics of Patients

\begin{tabular}{|c|c|c|c|}
\hline & $\begin{array}{l}\text { Reactions to } \mathrm{PN} \pm \mathrm{TN} \\
(n=102)\end{array}$ & $\begin{array}{l}\text { Reaction to TN Only } \\
\qquad(n=20)\end{array}$ & $\begin{array}{c}\text { Total } \\
(n=122)\end{array}$ \\
\hline Age at time of questionnaire (median, y) & 7.4 & 11.3 & 8.0 \\
\hline Percentage breastfed (median duration) & $83(6 \mathrm{mo})$ & $80(10 \mathrm{mo})$ & $83(6 \mathrm{mo})$ \\
\hline AS & $76 \%$ & $65 \%$ & $74 \%$ \\
\hline $\mathrm{AD}$ & $74 \%$ & $80 \%$ & $75 \%$ \\
\hline $\mathrm{AR}$ & $54 \%$ & $55 \%$ & $54 \%$ \\
\hline
\end{tabular}




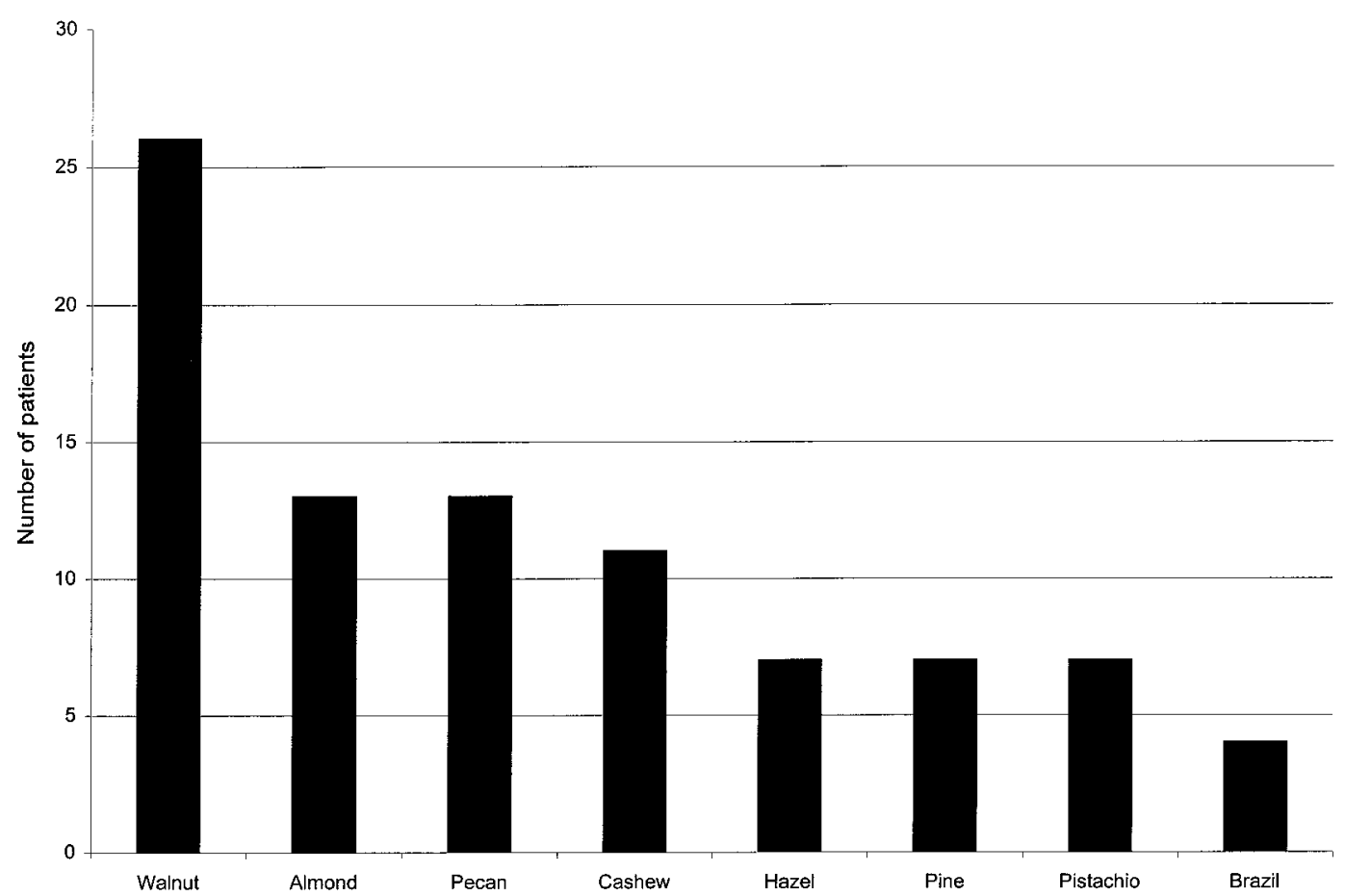

Fig 1. TN responsible for acute allergic reactions among 54 patients.

TABLE 2. Characteristics of First Episodes of Acute Reactions to PN and TN

\begin{tabular}{lcc}
\hline & PN $(n=102)$ & TN $(n=88)$ \\
\hline Age (median) first exposure & 22 mo (range, 6 to $108 \mathrm{mo})$ & 54 mo (range, 10 to 264 mo) \\
Age (median) first reaction & 24 mo (range, 6 to 108 mo) & 62 mo (range, 10 to 264 mo) \\
Reaction after first exposure & $72 \%$ & $71 \%$ \\
Time (median) to symptoms: & 3 min (range, 0.3 to 45 min) & 2 min (range, 0.3 to 30 min) \\
Organ systems involved in reaction & & \\
Skin only & $49 \%$ & $28 \%$ \\
Respiratory only & $2 \%$ & $11 \%$ \\
GI & $2 \%$ & $3 \%$ \\
Skin and respiratory & $17 \%$ & $31 \%$ \\
Skin and GI & $7 \%$ & $5 \%$ \\
GI and respiratory & $2 \%$ & $1 \%$ \\
All three systems & $21 \%$ & $21 \%$ \\
Hypotension/loss of consciousness & $0 \%$ & $0 \%$ \\
\hline
\end{tabular}

ments were described in 84 instances and included epinephrine (16), antihistamines (72), steroids (9), $\beta$-agonists (17), and cimetidine and intravenous fluids (1).

There were fewer accidental ingestions to $\mathrm{TN}$. Over a median period of 5.5 years from the initial reaction, $16(30 \%)$ of the 54 patients experienced 21 accidental ingestions. The median age at the time of the first accident was 9.6 years. Epinephrine was required in eight cases.

\section{Exposure History Among Patients With Acute Reactions to PN and TN}

The majority of those with acute reactions to PN denied the ingestion of any particular TN (ranging from $57 \%$ who denied ever eating almond to $85 \%$ who denied ever eating Brazil nut). The majority of patients were told to avoid all TN by the investigators or previous physicians. Many of the remaining patients did not have the occasion to eat $\mathrm{TN}$, were too young to be given $\mathrm{TN}$, or were unsure of their exposure history.
PN was almost universally consumed by lactating mothers, and $93 \%$ of the mothers consumed at least one TN while breastfeeding. Mothers were asked which foods they consumed and which they specifically avoided during lactation. Although many mothers did not recall ingesting any particular TN, fewer than six mothers strictly avoided PN or any specific TN during lactation.

\section{Results of Antigen-specific IgE Antibody Testing to PN} and TN

In 111 patients in whom serum was obtained (91 of the 102 patients with acute allergic reactions to $\mathrm{PN}$, with or without TN allergy, and all 20 patients with $\mathrm{TN}$ reactions), specific IgE antibody to $\mathrm{PN}$, walnut, hazel nut, Brazil nut, almond, pecan, pistachio, pine nut, and sesame was determined. Table 3 shows the results of the CAP-System FEIA for the four foods responsible for acute allergic reactions in 10 or more subjects (analysis was not performed for the remainder of the nuts because too few subjects reported acute reactions). Patients reporting reactions to PN, 
TABLE 3. PN- and TN-Specific IgE Levels $\left(\mathrm{kU}_{\mathrm{A}} / \mathrm{L}\right)$ in Patients With or Without Acute Reactions

\begin{tabular}{|c|c|c|c|c|c|c|c|}
\hline & \multicolumn{3}{|c|}{ Reactors } & \multicolumn{3}{|c|}{ Nonreactive } & \multirow[t]{2}{*}{$P$ Value* } \\
\hline & Mean & Median & $n$ & Mean & Median & $n$ & \\
\hline PN & 51.7 & 46.3 & 91 & 2.8 & 0.5 & 13 & $<.0001$ \\
\hline Almond & 17.1 & 3.8 & 11 & 14.5 & 1.8 & 25 & .81 \\
\hline Pecan & 18.3 & 1.9 & 11 & 1.6 & 0.5 & 10 & .027 \\
\hline
\end{tabular}

* Comparing those with a history of a reaction with those who have eaten the food without a reaction.

walnut, and pecan had significantly greater values of specific IgE antibodies toward the respective food than those ingesting the food without reactions. A total of 8 patients reported reactions to $\mathrm{PN}$ or TN, but had undetectable specific IgE antibody levels $(<0.35$ $\left.\mathrm{kU}_{\mathrm{A}} / \mathrm{L}\right)$ as follows: $\mathrm{PN}$ (4/91 reactions), walnut (4/ $25)$, almond (3/11), pecan $(2 / 11)$, pistachio $(1 / 7)$, and Brazil nut $(1 / 4)$. Among patients who believed that they never ingested a particular TN $(>60 \%$ of patients for each nut), the majority had levels of specific IgE antibodies $>0.34 \mathrm{kIU}_{\mathrm{A}} / \mathrm{L}$, with median values as follows: walnut, 1.2; hazel nut, 2.7; Brazil nut, 2.2; almond, 3.6; pecan, 1.7; pistachio, 1.9; and pine nut, 0.4 . The range of levels of specific IgE antibody for each food was from undetectable $\left(<0.35 \mathrm{kU}_{\mathrm{A}} / \mathrm{L}\right)$ to $>100 \mathrm{kIU}_{\mathrm{A}} / \mathrm{L}$.

Correlation coefficients of specific $\operatorname{IgE}$ antibodies for all 111 patients are shown in Table 4. In considering the group as a whole, specific IgE levels of all TN and sesame seed were highly correlated, whereas PN levels were not as highly correlated with walnut, pecan, or pistachio. The same analysis was performed on four subgroups: 1) 91 patients with acute reactions to $\mathrm{PN}$, with or without an acute reaction to a TN, 2) 31 patients with acute reactions to $P N$ and at least one TN, 3) 60 patients with reactions to $\mathrm{PN}$ but not to any TN, and 4) 20 patients with reactions to only TN. A similar pattern of correlation between the TN IgE antibody levels was noted in all subgroup analyses (data not shown). However, in the group of 20 patients with TN reactions alone, $\mathrm{PN}$-specific $\operatorname{IgE}$ levels were more highly correlated with hazel nut $\left(r_{\mathrm{s}}\right.$ $=0.91 ; P \leq .0001)$, almond $\left(r_{\mathrm{s}}=0.83 ; P \leq .0001\right)$, sesame $\left(r_{\mathrm{s}}=0.83 ; P \leq .0001\right)$, pine nut $\left(r_{\mathrm{s}}=0.74 ; P=\right.$ $.0002)$, walnut $\left(r_{\mathrm{s}}=0.66 ; P=.001\right)$, and pecan $\left(r_{\mathrm{s}}=\right.$ $0.48 ; P=.03)$.

\section{DISCUSSION}

Immediate hypersensitivity reactions to PN (a legume) and TN are a potential cause of anaphylaxis and death. ${ }^{6-8,13}$ The exact prevalence of allergic sensitization to $\mathrm{PN}$ and TN is not known, although estimates of PN sensitization among atopic patients has been reported to be $\sim 10 \% .{ }^{14} \mathrm{~A}$ recent study by Tariq and colleagues ${ }^{1}$ using skin prick testing found a sensitization rate of $1.2 \%$ and a reaction rate of $0.7 \%$ to $\mathrm{PN}$ or TN in a birth cohort of 1218 children on the Isle of Wight, UK, followed to age 4. Allergy to PN and $\mathrm{TN}$ appears to be rarely outgrown and remains an important cause of food-allergic reactions in adults. ${ }^{1,2,4,6,15}$ The results of our study highlight a number of features of acute reactions to PN and TN in children and raises questions that require additional study.

The diagnosis of PN and TN allergy in our study patients was based on a convincing history of an acute reaction to an isolated ingestion of the food. In 5 of 102 instances of acute reactions to PN and in 12 of 88 reactions to TN (among 9 patients in total), there was an undetectable level of specific $\operatorname{IgE}$ antibody levels to the food in question. This could represent a loss of sensitivity in some patients ${ }^{1}$ (although none described the ability to ingest the food without symptoms after having had the initial reaction), a misidentification of the responsible allergen, or lack of sensitivity of the test.

One striking feature of first reactions to PN was the young age at the time of the initial reaction (median, 24 months; range, 6 to 108 months). Similarly, studies in the United Kingdom showed that first reactions occurred by 24 months in approximately half of 60 patients who developed PN aller-

TABLE 4. Correlation $\left(r_{\mathrm{s}}\right)$ Between the Serum Levels of PN-, Sesame-, and TN-specific IgE in 111 Patients and in Subgroups With PN or Only TN Reactions ${ }^{a}$

\begin{tabular}{lcccccccc}
\hline \multicolumn{1}{c}{ PN } & Walnut & Hazel & Brazil & Almond & Pecan & Pistachio & Pine Nut & Sesame \\
\hline PN & $0.24(P=.01)$ & $0.60^{*}$ & $0.56^{*}$ & $0.58^{*}$ & $0.23(P=.02)$ & $0.26(P=.005)$ & $0.37^{*}$ & $0.50^{*}$ \\
Walnut & & $0.73^{*}$ & $0.61^{*}$ & $0.41^{*}$ & $0.89^{*}$ & $0.66^{*}$ & $0.53^{*}$ & $0.63^{*}$ \\
Hazel & & & $0.84^{*}$ & $0.73^{*}$ & $0.67^{*}$ & $0.68^{*}$ & $0.64^{*}$ & $0.83^{*}$ \\
Brazil nut & & & & $0.73^{*}$ & $0.54^{*}$ & $0.68^{*}$ & $0.59^{*}$ & $0.83^{*}$ \\
$\begin{array}{l}\text { Almond } \\
\text { Pecan }\end{array}$ & & & & $0.39^{*}$ & $0.43^{*}$ & $0.59^{*}$ & $0.78^{*}$ \\
$\begin{array}{l}\text { Pistachio } \\
\text { Pine nut }\end{array}$ & & & & & $0.65^{*}$ & $0.54^{*}$ & $0.55^{*}$ \\
$\begin{array}{l}\text { PN among PN reactors } \\
\text { only }(n=60)\end{array}$ & $0.33(P=.01)$ & $0.65^{*}$ & $0.64^{*}$ & $0.54^{*}$ & $0.40(P=.002)$ & $0.39(P=.003)$ & $0.34(P=.008)$ & $0.48^{*}$ \\
PN among TN reactors & $0.66(P=.0014)$ & $0.91^{*}$ & $0.59(P=.006)$ & $0.83^{*}$ & $0.48(P=.03)$ & $0.42(P=.07)$ & $0.74(P=.0002)$ & $0.83^{*}$ \\
$\quad$ only $(n=20)$ & & & & & & & & \\
\hline
\end{tabular}

${ }^{a}$ Correlation is weak if $r_{\mathrm{s}} \leq 0.4$, moderate if $r_{\mathrm{s}}$ is $0.4-0.7$, and strong if $r_{\mathrm{s}} \geq 0.7$.

${ }^{*} P<0.0001$. 
gy. ${ }^{6}$ The early onset of reactions to $\mathrm{PN}$ and the later age of onset (median, 62 months) of reactions to TN probably reflects the early ages of exposure to PN (especially in the form of peanut butter) in both countries.

The reactions reported in our patients were quite severe, with hives and/or angioedema in $89 \%$ and respiratory symptoms in $52 \%$ of patients. Of note, skin symptoms were not always a feature of an acute reaction. Although most symptoms occurred within minutes, some experienced a delay in their reaction (up to 45 minutes). We did not include patients who reported symptoms with an onset after 1 hour. Virtually all of the patients had epinephrine available for self-administration. The importance of prescribing self-injectable epinephrine to patients with a history of a major allergic reaction to these foods and for those with food allergies and asthma cannot be overemphasized. ${ }^{7}$

The high rate of accidental ingestions seen in this study, particularly for PN, is of clinical concern. Bock and Atkins ${ }^{2}$ found that among 32 patients with PN allergy followed for up to 14 years, $75 \%$ experienced an accidental ingestion. In the present study, accidental ingestions to PN occurred in 55\% of the patients over a median period of 5.4 years, with an average of two accidents per patient in those experiencing accidents. In contrast to the initial reactions that occurred primarily at home, a larger proportion of the accidental ingestions occurred in school. This fact underscores the importance of having medications and an emergency plan in place for the rapid administration of emergency medication, particularly epinephrine, when children with severe PN and TN allergies are outside of the home. ${ }^{7}$

The modes of accidental exposure to PN included hidden ingredients in processed foods, crosscontamination, sharing food with friends, and skin contact with peanut butter in school classroom projects. Restaurants also were particularly risky, especially Asian restaurants that may use PN in many foods, increasing the likelihood of cross-contamination. There were relatively fewer accidental ingestions of TN compared with PN, probably reflecting the more ubiquitous presence of $\mathrm{PN}$ in the food supply.

The relationship of $\mathrm{PN}$ and $\mathrm{TN}$ allergy has been addressed by a number of investigators, $2,6,9,10,16$ and it remains unclear whether patients with $\mathrm{PN}$ allergy are at an increased risk for TN allergy. In surveys in the United Kingdom, $50 \%$ of PN-allergic patients also reported reacting to at least one TN. $6,9,10$ Of the $102 \mathrm{PN}$-allergic patients in this report, 34\% reported having a reaction to a TN. This percentage of nut reactors may be lower than that reported in the United Kingdom because our patients are younger and have been advised to avoid TN. Among those who reported reactions to TN, $12(22 \%)$ reported having reactions to more than one $\mathrm{TN}$, a finding that has been reported previously ${ }^{6}$ and confirmed in double-blind, placebo-controlled food challenges. ${ }^{2}$

Evaluation of nut-specific IgE showed that a significant proportion of $\mathrm{PN}$-allergic children are sensitized to TN. Whether these sensitivities reflect a re- sponse to cross-reacting proteins (which may or may not be clinically relevant) or a general increase in propensity to form specific IgE antibody to allergenic proteins is unclear. The generally high correlation of specific IgE antibody levels among the foods seen in our patients could support either hypothesis. For example, $57 \%$ of our study population also were sensitive to egg. It is known that $\mathrm{PN}$-allergic patients have an increased rate of $\operatorname{IgE}$ sensitivity to egg, which would support the hypothesis that TN sensitivity is not peculiar to PN-allergic patients but merely reflects a greater likelihood to form IgE antibodies to allergenic proteins. Alternatively, crossreacting proteins may be playing a role. For example, hazel nut and sesame showed the highest cross-reactivity in our study, a correlation that was shown previously. ${ }^{11}$ Using RAST inhibition, Gillespie and colleagues ${ }^{16}$ found no cross-reactivity between PN and Brazil nut, but the RAST for pecan was inhibited by PN, Brazil nut, and walnut, whereas the RAST for PN was inhibited by pecan. Additional studies correlating RAST inhibition results and oral challenges will be needed to clarify these issues.

For PN, walnut, and pecan, we found that levels of specific IgE antibody levels were higher in subjects who experienced an acute reaction to the particular food than in those who eat the food with impunity. However, there was a great overlap in values among those with and without reactions. For example, many patients who ate almond had elevated almond-specific IgE levels. It is unknown whether this represents exposure with resulting clinically irrelevant, elevated $\mathrm{IgE}$ antibody or an immunologic response to crossreactive proteins. As with all IgE antibody tests for food allergy (skin prick tests or RAST), positive results do not always indicate clinical reactivity ${ }^{3}$ (poor sensitivity and specificity), whereas negative results have a high negative predictive value. A recent study in children with food allergy and atopic dermatitis showed that a PN-specific IgE level $>15 \mathrm{kU}_{\mathrm{A}} / \mathrm{L}$ had a $95 \%$ positive predictive value for experiencing a clinical reaction on ingestion of $\mathrm{PN}$, whereas an undetectable level had a $85 \%$ negative predictive value for a reaction. ${ }^{12}$ Interestingly, that study did not show any correlation between specific-IgE level and severity of reaction.

There are conflicting views on whether patients with PN allergy should avoid TN., ${ }^{2,9}$ As reported here and elsewhere, ${ }^{2}$ many $\mathrm{TN}$-allergic patients do not react to $\mathrm{PN}$ ingestion and visa versa. Although it may be overly restrictive, we and others ${ }^{9}$ advise complete avoidance of TN by PN-allergic children, except for any particular TN that was tolerated previously. Reasons for this recommendation include the concern that TN sensitivity appears to be severe and lifelong, that there is a potential for cross-contamination of $\mathrm{TN}$ products with $\mathrm{PN}^{8}$ and, finally, that it often is difficult to identify specific nuts in various processed foods. ${ }^{17-19}$

A large proportion of the patients report reactions to $\mathrm{PN}$ and TN on what was perceived to be their first exposure, a finding reported previously. $5,9,20$ Several possibilities may explain this phenomenon: recall bias, inadvertent or unknown exposure, sensitization 
by cross-reacting allergens, in utero exposure, and/or exposure through breast milk. ${ }^{21}$ The possibility of sensitization through breast milk is intriguing. In a population study on the Isle of Wight, ${ }^{1}$ there was no association between the duration of breastfeeding or history of maternal ingestion of nuts and sensitization as measured by skin prick tests and RAST. However, a survey of the families of $622 \mathrm{PN}$-allergic probands in the United Kingdom ${ }^{9}$ noted an increased prevalence of PN allergy in succeeding generations. It also was noted that mothers of younger probands (younger than age 6) were more likely to have consumed PN at least weekly while pregnant or breastfeeding than were mothers of older probands, suggesting to those workers that sensitization had occurred in utero or during lactation. The present study was not designed to investigate specifically routes or risks of sensitization, but several interesting points deserve comment. First, virtually all of the lactating mothers consumed $\mathrm{PN}$ and at least one TN. Second, a large proportion (from $50 \%$ to $82 \%$ ) of patients who did not report ever ingesting a particular nut had a detectable level of antibody to that nut, emphasizing the possibility that covert sensitization occurs, perhaps in part through sensitization from maternal intake. Additional research is needed on the relationship of $\mathrm{PN}$ and $\mathrm{TN}$ exposure in utero and during lactation to allergic sensitization to these antigens.

In this group of atopic patients referred for evaluation of acute reactions to $\mathrm{PN}$ and $\mathrm{TN}$, significant reactions occurred early in life, on what was often perceived to be the first exposure to the food, and frequently required emergency treatment. Accidental ingestions were common, sometimes life-threatening, required emergency treatment, and often occurred in locations outside of the home. Symptoms did not always involve the skin, although it was the organ system affected most often. Thirty-seven percent of PN-allergic patients also had acute reactions to at least one TN. Attempts to treat PN allergy with immunotherapy have had limited success with prohibitive side effects, ${ }^{22}$ and the only current treatment for these allergies is strict avoidance of the offending food and prompt recognition and treatment of reactions. These findings emphasize the need for education of families, patients, caregivers, and health care workers in PN and TN avoidance and treatment of reactions.

\section{ACKNOWLEDGMENTS}

We thank Debbie Ho, BA, and Sara Cooke, AB, for their expert laboratory assistance; Lynn Keible, RN, for her assistance in pa- tient care; and Pharmacia and Upjohn Diagnostics (Uppsala, Sweden) for supplying the FEIA CAP-RAST materials. We also gratefully acknowledge the support of the Clarissa Sosin Allergy Research Foundation, Inc, and the John and Susan Tomich Family Foundation.

\section{REFERENCES}

1. Tariq S, Stevens M, Matthews S, Ridout S, Twiselton R, Hide D. Cohort study of peanut and tree nut sensitization by the age of four years. $\mathrm{Br}$ Med J. 1996;313:514-517

2. Bock SA, Atkins FM. The natural history of peanut allergy. J Allergy Clin Immunol. 1989;83:900-904

3. Bock SA. The natural history of food sensitivity. J Allergy Clin Immunol. 1982;69:173-177

4. Atkins FM, Steinberg SS, Metcalfe DD. Evaluation of immediate adverse reactions to foods in adult patients. II. A detailed analysis of reaction patterns during oral food challenge. J Allergy Clin Immunol. 1985;75: 356-363

5. Fries JH. Peanuts: allergic and other untoward reactions. Ann Allergy. 1982;48:220-226

6. Ewan P. Clinical study of peanut and nut allergy in 62 consecutive patients: new features and associations. Br Med J. 1996;312:1074-1078

7. Sampson HA, Mendelson LM, Rosen JP. Fatal and near-fatal anaphylactic reactions to food in children and adolescents. $N$ Engl J Med. 1992;327:380-384

8. Sampson HA. Peanut anaphylaxis. J Allergy Clin Immunol. 1990;86:1-3

9. Hourihane JO'B, Dean TP, Warner JO. Peanut allergy in relation to heredity, maternal diet, and other atopic diseases: results of a questionnaire survey, skin prick testing, and food challenges. Br Med J. 1996; 313:518-521

10. Loza C, Brostoff J. Peanut allergy. Clin Exp Allergy. 1995;25:493-502

11. Vocks E, Borga A, Szliska C, Seifert HU, Burow G, Borelli S. Common allergenic structures in hazelnut, rye grain, sesame seeds, kiwi, and poppy seeds. Allergy. 1993;48:168-172

12. Sampson H, Ho D. Relationship between food-specific IgE concentrations and the risk of positive food challenges in children and adolescents. J Allergy Clin Immunol. 1997;100:444-451

13. Yunginger JW, Sweeney KG, Sturner WQ, et al. Fatal food-induced anaphylaxis. JAMA. 1988;260:1450-1452

14. Hoffman DR, Haddad ZH. Diagnosis of IgE-mediated reactions to food antigens by radioimmunoassay. J Allergy Clin Immunol. 1974;54:165-173

15. Metcalfe DD. Food allergy in adults. In: Metcalfe DD, Sampson HA, Simon RA, eds. Food Allergy: Adverse Reactions to Foods and Food Additives. Cambridge, UK: Blackwell Science; 1997:183-192

16. Gillespie DN, Nakajima S, Gleich GJ. Detection of allergy to nuts by the radioallergosorbent test. J Allergy Clin Immunol. 1976;57:302-309

17. Moneret-Vautrin DA, Hatahet R, Kanny G. Risks of milk formulas containing peanut oil contaminated with peanut allergens in infants with atopic dermatitis. Pediatr Allergy Immunol. 1994;5:184-188

18. Keating MU, Jones RT, Worley NJ, Shively CA, Yunginger JW. Immunoassay of peanut allergens in food-processing materials and finished foods. J Allergy Clin Immunol. 1990;86:41-44

19. Gern J, Yang E, Evrard H, Sampson H. Allergic reactions to milkcontaminated "non-dairy" products. N Engl J Med. 1991;324:976-979

20. Van Asperen P, Kemp AS, Mellis CM. Immediate food hypersensitivity reactions on the first known exposure to the food. Arch Dis Child. 1983;58:253-256

21. Gerrard JW, Perelmutter L. IgE-mediated allergy to peanut, cow's milk, and egg in children with special reference to maternal diet. Ann Allergy. 1986;56:351-354

22. Nelson HS, Lahr J, Rule R, Bock A, Leung D. Treatment of anaphylactic sensitivity to peanuts by immunotherapy with injections of aqueous peanut extract. J Allergy Clin Immunol. 1997;99:744-751 


\section{Clinical Features of Acute Allergic Reactions to Peanut and Tree Nuts in Children}

Scott H. Sicherer, A. Wesley Burks and Hugh A. Sampson

Pediatrics 1998;102; 6

DOI: $10.1542 /$ peds.102.1.e6

Updated Information \& Services

\section{References}

Subspecialty Collections

Permissions \& Licensing

Reprints including high resolution figures, can be found at: http://pediatrics.aappublications.org/content/102/1/e6

This article cites 21 articles, 3 of which you can access for free at: http://pediatrics.aappublications.org/content/102/1/e6.full\#ref-list-1

This article, along with others on similar topics, appears in the following collection(s):

\section{Coding Corner}

http://classic.pediatrics.aappublications.org/cgi/collection/coding_cor ner

Information about reproducing this article in parts (figures, tables) or in its entirety can be found online at:

https://shop.aap.org/licensing-permissions/

Information about ordering reprints can be found online:

http://classic.pediatrics.aappublications.org/content/reprints

Pediatrics is the official journal of the American Academy of Pediatrics. A monthly publication, it has been published continuously since . Pediatrics is owned, published, and trademarked by the American Academy of Pediatrics, 141 Northwest Point Boulevard, Elk Grove Village, Illinois, 60007. Copyright @ 1998 by the American Academy of Pediatrics. All rights reserved. Print ISSN:

\section{American Academy of Pediatrics}




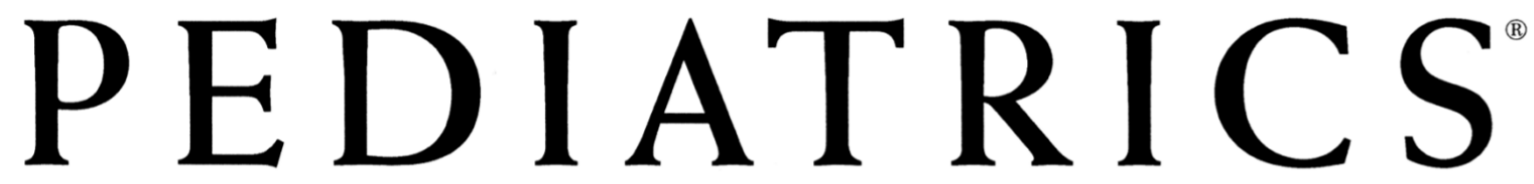

OFFICIAL JOURNAL OF THE AMERICAN ACADEMY OF PEDIATRICS

\section{Clinical Features of Acute Allergic Reactions to Peanut and Tree Nuts in Children}

Scott H. Sicherer, A. Wesley Burks and Hugh A. Sampson

Pediatrics 1998; 102; 6

DOI: 10.1542/peds.102.1.e6

The online version of this article, along with updated information and services, is located on the World Wide Web at:

http://pediatrics.aappublications.org/content/102/1/e6

Pediatrics is the official journal of the American Academy of Pediatrics. A monthly publication, it has been published continuously since . Pediatrics is owned, published, and trademarked by the American Academy of Pediatrics, 141 Northwest Point Boulevard, Elk Grove Village, Illinois, 60007. Copyright $\Subset 1998$ by the American Academy of Pediatrics. All rights reserved. Print ISSN:

\section{American Academy of Pediatrics}

